\title{
Effects of nutrition education on recurrent coronary events after percutaneous coronary intervention: $A$ randomized clinical trial
}

\author{
Lis Proença Vieira ${ }^{*}$, Moacyr Roberto Cucê Nobre ${ }^{2}$ and Jonas Augusto Cardoso da Silveira ${ }^{3}$
}

\begin{abstract}
Background: Changes in lifestyle include a healthy diet. However, due to different educational approaches, the effects of nutritional counselling are still not very encouraging and require further study. The objective of this study was to analyse the effectiveness of a nutrition education intervention program on mortality and recurrence of cardiovascular events evaluated after one and four years of follow-up.
\end{abstract}

Methods: A randomized clinical trial was performed at a public hospital in Brazil with 200 patients who had recently undergone elective percutaneous coronary intervention (PCI). In addition to the traditional care, the patients allocated to the intervention group attended nutrition education workshops that adopted a constructivist approach towards behavioural change for six months. Primary outcome was death, and secondary outcomes were acute myocardial infarction (AMI), revascularization with re-PCl, or coronary artery bypass graft (CABG) surgery. The magnitude of the first year effect was calculated by the absolute risk reduction, and the risk ratio was calculated as a measure of the cumulative incidence of events after four years. The critical p-value was assumed as 5\%.

Results: After one year of follow-up, in the intervention and control groups, respectively, there were 5 and 7 deaths $(p=0.53) ; 5$ and 6 AMls $(p=0.73) ; 4$ and 6 re-PCls $(p=0.50)$; and 4 and 4 CABGs $(p=0.98)$. After four years, the risk ratios between intervention and control groups were 0.75 (95\% Cl 0.35-1.58) for death, 0.89 (95\% Cl 0.34-2.28) for AMl, 0.86 (95\% Cl 0.40-1.84) for re-PCl, and 1.14 (95\% Cl 0.38-3.40) for CABG.

Conclusion: Although differences in events between the two groups were not significant, data suggest that the lower number of events observed in the intervention group is most notable with the longer follow-up.

Trial registration number: NCT01028066. Registered 8 December 2009, retrospectively registered.

Keywords: Food and nutrition education, Mortality, Food consumption, Coronary artery disease, Secondary prevention

\section{Background}

Changes in lifestyle, such as smoking cessation; regular physical activity; a diet rich in fruits, vegetables, whole grains, and fish; and a healthy weight can reduce the incidence of coronary heart disease by over $80 \%$ [1].

The Lifestyle Heart Trial was the first randomized, controlled study assessing the regression of coronary

\footnotetext{
*Correspondence: lis.vieira@incor.usp.br

${ }^{1}$ Nutrition and Dietetic Service, Heart Institute (InCor) do Hospital das Clínicas da Faculdade de Medicina da Universidade de São Paulo, Av. Dr. Enéas de Carvalho Aguiar, 44. Cerqueira César, São Paulo, SP CEP: 05403-000, Brazil

Full list of author information is available at the end of the article
}

lesions resulting from changes in lifestyle [2], and other studies have since been reporting positive effects in reducing the risk of ischemic disease [3, 4], and the recurrence of cardiovascular events [5]. However, due to different educational approaches-when the theoretical background is a concern for researchers-and the lack of standardization among protocols, the effects of nutritional counselling are still not very encouraging [6] and require further study.

The use of health education to help people adopt healthier lifestyles has been supported by some researchers [7, 8]. Compliance with lifestyle changes 
remains a challenge, because it depends not only on understanding the health information but also on the motivation to engage on such habits. Thus, cognitivebehavioural strategies are currently emerging as a key component in behavioural change interventions and are focused on changing how individuals think about themselves, their attitudes, and how they can change their lifestyle, using resources, such as concrete goals, feedback and positive reinforcement, and relapse prevention [9].

The objective of this randomized trial was to analyse the effectiveness of a nutrition education intervention on mortality and the recurrence of cardiovascular events in patients who had previously undergone percutaneous coronary intervention (PCI).

\section{Methods}

\section{Study design}

We conducted a randomized clinical trial among outpatients who had recently undergone PCI and were receiving standard clinical, surgical, and nutritional care after discharge; in addition to the traditional care, the patients allocated to the intervention group attended nutrition education workshops.

The sample size was calculated based on the results from Lisspers et al. [5], who assessed the recurrence of cardiovascular mortality, acute myocardial infarction (AMI), coronary artery bypass graft (CABG), or re-PCI in chronic coronary patients after a PCI. The prevalence of at least one of these events was 30 and 54\% in the presence and absence of a behavioural change intervention program, respectively. An $\alpha$ error $=5 \%, \beta$ error $=$ $20 \%$, and a $1: 1$ ratio between the control and intervention groups were used. The estimated sample was 148 individuals to which was added a loss margin of up to $35 \%$, yielding a final sample of 200 patients.

The recruitment occurred from April 2008 to January 2009 , the period necessary for the inclusion of the calculated sample. All 343 patients assisted by the Brazilian Unified Health System, consecutively admitted to the hospital's hemodynamic unit to undergo elective PCI, were considered eligible (no neurological or cognitive impairment). However, 143 were excluded for failing to meet the single inclusion criterion, which was availability to participate in the nutrition education workshops. All patients received specific food and nutritional instruction [10] at discharge from a nutritionist after undergoing angioplasty.

A trained nutritionist collected data from the patients who agreed to participate in the study, and each patient's clinical history was obtained from medical records. After data collection was completed, the patients were confidentially and randomly (random numbers table) allocated to the intervention and control groups by the researcher. The randomization sequence was generated at the website OpenEpi.com [11] by a person not involved in the research. The table was stored in an opaque envelope, inaccessible to the interviewer. Although the allocation was confidential, blinding was not possible given the nature of the educational intervention.

All patients were instructed about the study and signed an informed consent form. The study was approved by local and Brazilian Ethics Committees.

\section{Nutrition intervention}

The intervention consisted of four nutrition education workshops during a six-month period, conducted at the institution itself, lasting approximately one hour. Each meeting included 10 patients, who could be accompanied by a relative and was offered at different time periods (morning or afternoon) and on different days of the week to better meet the needs of each participant. The first three workshops were biweekly, and the fourth and the last one was conducted six months after the first.

We developed each nutrition education workshop using a constructivist educational approach [12] directed towards the adoption of a healthy diet (energy balance for a healthy weight; reduction of energy intake from fat; replacing saturated and trans fats with unsaturated fat; increased consumption of fruits, vegetables, whole grains, and legumes; reduction of sugar and sodium intake) $[13,14]$, and the prevention and control of cardiovascular risk factors [9]. The workshops followed the structure proposed by Paulo Freire, consisting of research, schematization, and awareness stages $[15,16]$ adapted to the nutrition education context and meeting the assumption of the joint construction of knowledge, with active participation of the groups. Physical activity was not assessed or discussed with the patients.

Two professionals led the workshops: a coordinator of activities and a participant observer. The participant observer collected data through a field diary and recording sessions, so the points not clearly treated could be addressed at the next meeting. The observations during the workshops guided the techniques to support the discussion in the course of the sessions and to allow obtaining knowledge based on the needs of the participants and not the researcher, as the adopted methodology.

In the first workshop, food replicas were used to compose initial examples of meals, from which participants would choose one according to their preference, with the objective of surveying eating habits and the difficulty of healthy choices. In the second workshop, the replicas were distributed throughout a space representing a supermarket. The participants chose foods they "would buy" and explained their contents. With the help of a 
nutritionist, the concepts of portion size, nutritional composition of foods, and the quality of a healthy diet were explained. In the third workshop, an acrylic pyramid was used that was filled with foods "purchased" in the previous workshop activity, and other foods could be added. Subsequently, the patients were encouraged to discuss the function of foods and group them according to similar nutritional properties and in what quantity they should be consumed, with the objective of identifying portions and making correct food substitutions. The last workshop was reinforcement, wherein the participants were asked about their changes in eating habits. The inadequacies of two different menus were discussed, which should be noticed and corrected by the participants, to stimulate a critical, albeit not punitive, view regarding food.

In this way, we emphasized dietary patterns rather than individual dietary components, because dietary patterns refer to a variety of foods and offer the opportunity to characterize the overall composition and quality of the eating behaviours [17].

After one year of monitoring, the patients in the control group were invited to a final meeting, where they received nutritional guidance along the lines of the reinforcement applied to the intervention group.

The adherence to and changes in subjects' dietary intake was measured by a semi-quantitative food frequency questionnaire, which was developed to investigate potential relationships between diet and noncommunicable diseases [18], and posteriorly, used to measure daily intake of fruit and vegetables by elderly [19]. It was adapted after a pre-test study, as previously described [20], and the food intake of the previous year was evaluated. The questionnaires were applied by a trained nutritionist at the moment of recruitment and after one year of follow-up, and they were input twice into the DietSys Analysis Software, of the USA National Cancer Institute. To eliminate the effect of the total energy in the analysis of the nutrients, an adjustment was made for total energy by using the residual adjustment method [21]. Additionally, we applied an algorithm [22], in which individuals reported whether they had ever changed their eating habits to a healthier pattern and to identify the stages of change in healthy eating, according to the transtheoretical model [23]. In the subsequent years, people from intervention group were contacted by telephone and we asked them to rate their adherence from 0 to 5 .

\section{Outcome measures}

The primary outcome was death and secondary outcomes were AMI, revascularization with re-PCI, or CABG surgery, as well as the composite endpoints (presence of at least one cardiovascular event), which were measured after one year of follow-up, by the end of the trial period. The same clinical outcomes were assessed after four years of follow-up as part of this prospective study. All outcomes were reported by the patients and checked in the electronic medical records.

\section{Data analysis}

The intention-to-treat analysis was performed using the statistical package Stata/ME 11.0 (Stata Corp, College Station, TX).

The categorical variables are expressed as relative frequencies and the numeric variables are expressed using measures of central tendency (mean and median) and variability (standard deviation, 95\% confidence interval [95\% CI] and interquartile range).

The chi-square test was performed to identify the effect of the intervention in both the intervention and control groups. The magnitude of the first year effect was calculated by the absolute risk reduction, subtracting the percentage of subjects with events in the treatment group from the percentage in the control group. In addition, we tested changes in the smoking status and medication use (statins, antihypertensives, and hypoglycaemics) during the intervention period.

The risk ratio was calculated as a measure of the cumulative incidence of events after four years, and the cumulative proportions of subjects without cardiovascular events by time were analysed with Kaplan-Meier using the log-rank test to compare the equality of survivor functions between groups. Hazard ratios were generated by Cox proportional hazards model for each outcome.

The comparisons between the intervention and control groups regarding the dependent variables with normal distribution in the beginning and end of the study were performed using the $t$ test for independent samples; the Mann-Whitney test was used for the variables with nonparametric distributions. The critical p-value was assumed as $5 \%$.

\section{Results}

The randomization process and the number of subjects at the end of the study are shown in Fig. 1. No significant differences were observed after the random allocation of subjects to the intervention and control groups, except for the number of subjects with dyslipidaemia. No difference occurred regarding the drug treatment prescribed to both groups (Table 1). An additional file shows raw database [see Additional file 1].

Despite the absolute risk reduction, there was no difference in mortality or in the recurrence of cardiovascular events between the groups, after 1 year of follow-up (Table 2). The number needed to treat and prevent one death was 50 individuals. 


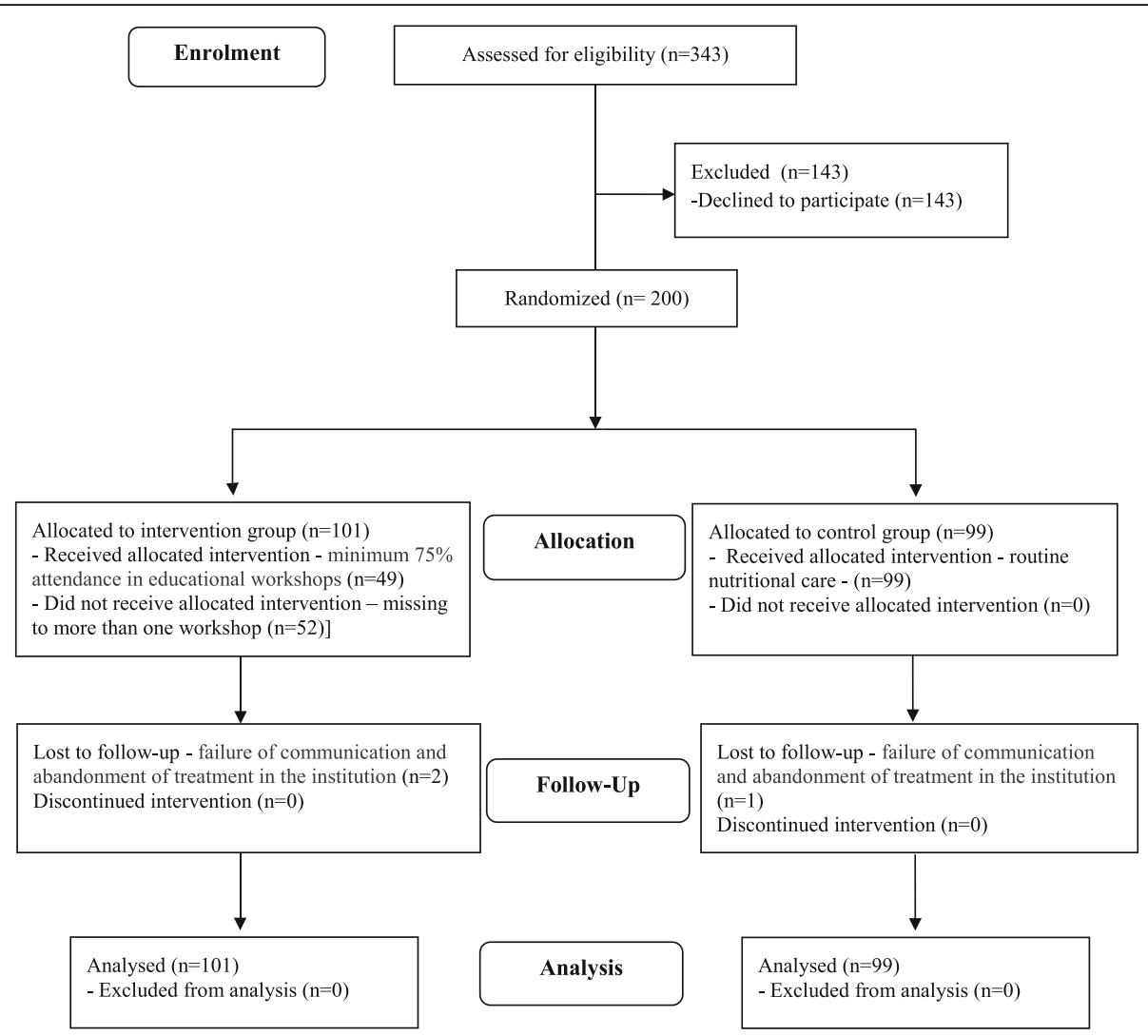

Fig. 1 Description of a figure: Flow diagram from the randomized clinical trial

Changes in smoking status and medication use after one-year follow-up could be potential confounding variables, so they were tested. There was no difference in smokers who attempted to stop smoking $(p=0.33)$ and prescriptions drugs: statins $(p=0.18)$, antihypertensive $(p=0.12)$, and hypoglycaemic $(p=0.46)$ therapies between groups.

After four years of follow-up, there was no difference in the incidence of death and recurrence of cardiovascular events in the intervention and the control groups (Table 3). Over four years, there were more events in the control group than in the intervention group, but not enough to guarantee a difference between them (Table 4).

Monitoring changes in food intake revealed both groups decreased total calories and all nutrients intake (difference intra-groups), but the intervention group had a significant reduction of $2.31 \mathrm{~g} /$ day in the saturated fat $(p=0.02)$ and a significant positive variation of $2.70 \mathrm{~g} /$ day of fiber $(p=0.03)$ and $318.43 \mathrm{mg} /$ day of potassium $(p=0.01)$ (variation between groups), once the reduction in the fiber and potassium consumptions was smaller than the control group, after one-year follow-up (Table 5). An additional file shows data of absolute and adjusted nutrient values [see Additional file 2].
Individuals with a higher level of education seem to adhere more to healthier diets, so we tested education and nutrients with significant variation between intervention and control groups. There was no difference in saturated fat $(p=0.62)$, fiber $(0.48)$ and potassium $(p=0.31)$ intakes in those with more or less than four years of study.

At the end of the first year, there was an increase in the number of individuals in the motivation stage of maintenance from 31 to $65 \%$ in the control group and from 42 to $76 \%$ in the intervention group without difference among the different stages (precontemplation, contemplation, preparation, action and maintenance) between groups $(p=0.44)$. During the observational study, $79.5 \%$ of patients who had participated in the workshops classified themselves as greater than three for their adherence to a healthy diet.

\section{Discussion}

The lifestyle intervention developed in this study and conducted among patients with established coronary artery disease had no significant impact on death or any major cardiovascular events. Thus, we consider that the effect of the intervention was not strong enough to promote additional benefits, considering the usual care 
Table 1 Baseline characteristics of participants $(n=200)$ according to study group. São Paulo, 2015

\begin{tabular}{|c|c|c|c|}
\hline Characteristics & $\begin{array}{l}\text { Intervention } \\
(n=101)\end{array}$ & $\begin{array}{l}\text { Control } \\
(n=99)\end{array}$ & $\mathrm{p}$ \\
\hline Male - n (\%) & $70(69)$ & $70(71)$ & 0.83 \\
\hline Age (years) ${ }^{a}$ & $60.4 \pm 9.1$ & $59.6 \pm 10.4$ & 0.55 \\
\hline Education (years) ${ }^{b}$ & $5.0(4-11)$ & $6.0(4-11)$ & 0.91 \\
\hline \multicolumn{4}{|c|}{ Type of coronary angioplasty - n (\%) } \\
\hline Balloon & $6(5.9)$ & $3(3.1)$ & 0.32 \\
\hline Conventional stent & $88(87.2)$ & $83(83.8)$ & 0.51 \\
\hline Pharmacological stent & $7(6.9)$ & $13(13.1)$ & 0.14 \\
\hline \multicolumn{4}{|l|}{ Clinical history- n (\%) } \\
\hline Systemic arterial hypertension & $83(82.2)$ & $88(88.9)$ & 0.18 \\
\hline Dyslipidaemia & $70(69.3)$ & $82(82.8)$ & 0.03 \\
\hline Type 2 diabetes & $41(40.6)$ & $36(36.4)$ & 0.54 \\
\hline $\begin{array}{l}\text { Family history of premature } \\
\text { coronary heart disease }\end{array}$ & $45(44.6)$ & $34(34.3)$ & 0.14 \\
\hline $\begin{array}{l}\text { Previous acute myocardial } \\
\text { infarction }\end{array}$ & $44(43.6)$ & $42(42.4)$ & 0.87 \\
\hline Previous angioplasty & 19 (18.8) & $24(24.2)$ & 0.35 \\
\hline Heart surgery & $9(8.9)$ & $13(13.1)$ & 0.34 \\
\hline \multicolumn{4}{|l|}{ Smoking status - n (\%) } \\
\hline Non-smoker & $64(63.4)$ & $61(61.6)$ & 0.30 \\
\hline Former smoker & $13(12.9)$ & $20(20.2)$ & \\
\hline Smoker & $24(23.8)$ & $18(18.2)$ & \\
\hline \multicolumn{4}{|l|}{ Medication use - n (\%) } \\
\hline Antihypertensive agents & $73(72.3)$ & $82(82.8)$ & 0.07 \\
\hline Oral hypoglycaemic agents & $32(31.7)$ & $23(23.2)$ & 0.18 \\
\hline Statins & $50(49.5)$ & $57(57.6)$ & 0.25 \\
\hline Antiarrhythmic agents & $59(58.4)$ & $63(63.6)$ & 0.45 \\
\hline
\end{tabular}

${ }^{a}$ Values are mean \pm standard deviation

${ }^{b}$ Values are median and interquartile range

delivered in the hospital, especially because it is a reference cardiology centre where patients have the most qualified professionals and access to technology and proper medication. Perhaps in other less-privileged environments, the results would be different. The fact that half of the intervention participants did not attend at least $75 \%$ of the educational workshops may also have impaired the effectiveness of the proposed theoretical background, which uses sequential stages for new learning of dietary and behavioural skill. This finding reinforces the evidence on how difficult it is to deal with adherence, even in individuals in an advanced stage of motivation, what can be an influence of the cardiovascular event itself in the change of eating habits, in attempt to restore health [20], and considering the availability to attend the workshops was an inclusion criterion.

A literature review of the effect of lifestyle and dietary changes on mortality in coronary artery disease patients estimated the risk reduction potential for combinations of individual dietary goals to be $45 \%$ [24]. A gap still exists in the literature as to how lifestyle can contribute to secondary prevention in patients with heart disease.

The Look AHEAD Trial, with over 5000 patients with type 2 diabetes for almost 10 years, tried to show a difference in cardiovascular outcomes with an intensive lifestyle intervention to weight loss and still failed to do that in terms of having statistical power for their primary outcomes, probably because there was a very low overall rate of events in both groups [25].

Lisspers et al. [5] found a significant actual risk reduction of $23 \%$ and relative risk reduction of $43 \%$ for at least one cardiovascular event in stable patients after PCI, but the average length of the follow-up was 6.5 years. During the first year, they also observed no difference between the groups regarding the number of subjects experiencing coronary events: 11 (23.9\%) in the intervention group and $9(22.0 \%)$ in the control group.

Positive impacts on lifestyle factors were shown among the studies describing cardiac rehabilitation programs with high intensity ( $>20$ contacts) and long duration ( $>3$ months) [26]. It is possible that our minor intervention was not strong enough to produce significant results in short- and long-term major outcomes, but we did note positive changes in dietary intake, similarly the study of Bemelmans et al. [6], whose nutritional education programme with group sessions changed dietary intake, but had no additional positive effects on

Table 2 Incidence of recurrence of cardiovascular events and mortality in the control and intervention groups, and absolute risk reduction, after one-year follow-up. São Paulo, 2015

\begin{tabular}{|c|c|c|c|c|}
\hline Events & $\begin{array}{l}\text { Intervention }(n=101) \\
\mathrm{n}(\%)\end{array}$ & $\begin{array}{l}\text { Control }(n=99) \\
\mathrm{n}(\%)\end{array}$ & $\operatorname{ARR}(95 \% \mathrm{Cl})$ & $p$ \\
\hline Mortality & $5(4.95)$ & $7(7.07)$ & $-2.12 \%(-8.71 ; 4.47)$ & 0.53 \\
\hline AMI & $5(4.95)$ & $6(6.06)$ & $-1.11 \%(-7.43 ; 5.21)$ & 0.73 \\
\hline $\mathrm{Re}-\mathrm{PCl}$ & $4(3.96)$ & $6(6.06)$ & $-2.10 \%(-8.15 ; 3.95)$ & 0.50 \\
\hline CABG & $4(3.96)$ & $4(4.04)$ & $-0.08 \%(-5.51 ; 5.35)$ & 0.98 \\
\hline Composite endpoints & 11 (10.89) & $13(13.13)$ & $-2.24 \%(-11.3 ; 6.77)$ & 0.63 \\
\hline
\end{tabular}


Table 3 Incidence of recurrence of cardiovascular events and mortality in the control and intervention groups, and risk ratio, after four-year follow-up. São Paulo, 2015

\begin{tabular}{|c|c|c|c|c|}
\hline Events & $\begin{array}{l}\text { Intervention }(n=101) \\
\mathrm{n}(\%)\end{array}$ & $\begin{array}{l}\text { Control }(n=99) \\
\mathrm{n}(\%)\end{array}$ & $\mathrm{RR}^{\mathrm{a}}(95 \% \mathrm{Cl})$ & $p$ \\
\hline Mortality & $10(9.90)$ & $13(13.13)$ & $0.75(0.35 ; 1.58)$ & 0.15 \\
\hline AMI & $7(6.93)$ & $8(8.08)$ & $0.89(0.34 ; 2.28)$ & 0.27 \\
\hline Re-PCl & $10(9.90)$ & $12(12.12)$ & $0.86(0.40 ; 1.84)$ & 0.12 \\
\hline CABG & $6(5.94)$ & $5(5.05)$ & $1.14(0.38 ; 3.40)$ & 0.16 \\
\hline Composite endpoints & $20(19.80)$ & $24(24.24)$ & $0.84(0.51 ; 1.40)$ & 0.05 \\
\hline
\end{tabular}

$A M I$ acute myocardial infarction, $R e-P C l$ re-percutaneous coronary intervention, $C A B G$ coronary artery bypass graft, $R R$ Risk Ratio

adjusted for dyslipidaemia

established cardiovascular risk factors after three years of follow-up.

The higher fiber and potassion consumption in the intervention group are probably related to a more prudent dietary pattern [17] characterized by high intakes of fruits and vegetables, which are sources of these nutrients. In the same way, the reduction in saturated fat intake is directed towards food choices like lean meats and low fat dairy product. The constructivist educational approach seemed to reach all the participants, even those with lower educational level. How to reach the greatest possible adherence to lifestyle changes in patients with coronary heart disease has not been identified. Recently, a group-based minimally prescriptive lifestyle modification program achieved significant improvements in body composition and physical and cardio-metabolic fitness [27].

The intervention proposed in this study causes no harm, is low in cost, and can be used as a preventive approach at both referral hospitals and primary health care units. A less prescriptive dietary approach should be encouraged in other investigations and in clinical practice to promote self-care and social awareness in health. In contrast to the traditional weight-centred approach, a qualitative approach is based on the principle of advocating healthy changes in food selection rather than adherence to prescriptive diets that involves calorie counting [28].
The strength of this study lies in the participatory educational intervention and the patient-centred approach. We focused on behavioural change without rigorous control of compliance, because the objective was to observe how health practices are sustained in daily life, which may differ from intensively controlled contexts. However, some weaknesses were noted during the study. The low intensity of the intervention, the number that actually completed the intervention, and the low event rate may have been determining factors of the limited effect sample size. Additionally, the sample size failed to provide enough power for the analyses, because of the underestimation of the number of events; therefore, a larger sample size and longer follow-up time might provide more accurate results, considering our estimations. The monitoring of adherence after the first year was quite subjective, so we consider a study limitation to be the lack of an objective and systematic measure during the cohort period.

The effectiveness of this kind of intervention remains inconclusive and further research should be conducted overcoming the limitations described above. Although there was no effect on the primary outcome, we consider that the intervention developed here -due to its theoretical background- is promising to produce better outcomes, as beneficial modifications in food consumption and other possible lifestyle changes that could improve quality of life.

Table 4 Event-free probability in patients after PCI, at 12, 24, 36, and 48 months, proportionality of risk and Cox regression for the respective risks of cardiovascular events. São Paulo, 2015

\begin{tabular}{|c|c|c|c|c|c|c|c|c|c|c|}
\hline \multirow{3}{*}{ Cardiovascular events } & \multicolumn{8}{|c|}{ Event-free probability (months) } & \multirow{3}{*}{$\begin{array}{l}\text { p-value } \\
\text { (log-rank) }\end{array}$} & \multirow[t]{3}{*}{ HR $(95 \% \mathrm{Cl})$} \\
\hline & \multicolumn{4}{|c|}{ Intervention } & \multicolumn{4}{|c|}{ Control } & & \\
\hline & 12 & 24 & 36 & 48 & 12 & 24 & 36 & 48 & & \\
\hline Death & 0.97 & 0.96 & 0.93 & 0.92 & 0.94 & 0.94 & 0.89 & 0.88 & 0.33 & $0.64(0.26-1.57)$ \\
\hline AMI & 0.97 & 0.96 & 0.96 & 0.95 & 0.95 & 0.95 & 0.94 & 0.92 & 0.51 & $0.68(0.22-2.15)$ \\
\hline $\mathrm{Re}-\mathrm{PCl}$ & 0.98 & 0.96 & 0.94 & 0.92 & 0.95 & 0.93 & 0.89 & 0.88 & 0.38 & $0.67(0.27-1.66)$ \\
\hline CABG & 0.98 & 0.97 & 0.97 & 0.96 & 0.97 & 0.97 & 0.97 & 0.96 & 0.97 & $0.97(0.24-3.88)$ \\
\hline Composite endpoints & 0.91 & 0.89 & 0.86 & 0.82 & 0.88 & 0.86 & 0.79 & 0.76 & 0.30 & $0.72(0.39-1.34)$ \\
\hline
\end{tabular}

$A M I$ acute myocardial infarction, $P C l$ percutaneous coronary intervention, $C A B G$ coronary artery bypass graft, $H R$ hazard ratio 
Table 5 Daily food intake in the intervention and control groups and its variation after one-year follow up. São Paulo, 2015

\begin{tabular}{|c|c|c|c|c|c|c|c|c|}
\hline & \multicolumn{3}{|l|}{ Intervention (I) } & \multicolumn{3}{|l|}{ Control (C) } & \multirow{2}{*}{$\begin{array}{l}\text { Variation: I-C } \\
\text { Mean } \\
\text { (CI 95\%) }\end{array}$} & \multirow[t]{2}{*}{$p$} \\
\hline & Initial intake $(n=101)$ & Final intake $(n=76)$ & $\begin{array}{l}\text { Difference: Final - Initial (Cl } \\
\text { 95\%) }\end{array}$ & Initial intake $(n=99)$ & Final intake $(n=76)$ & $\begin{array}{l}\text { Difference: Final - Initial (Cl } \\
\text { 95\%) }\end{array}$ & & \\
\hline Calories (Kcal) & $\begin{array}{l}2539.03(2379.25 ; \\
2698.81)\end{array}$ & $\begin{array}{l}2031.04 \text { (1902.44; } \\
\text { 2159.64) }\end{array}$ & $-393.58^{*}(-526.54 ;-260.61)$ & $\begin{array}{l}2531.11(2392.74 \\
2669.47)\end{array}$ & $\begin{array}{l}2080.95 \text { (1945.71; } \\
2216.19)\end{array}$ & $-452.27^{*}(-585.72 ;-318.82)$ & $\begin{array}{l}+58.70(-128.16 \\
245.55)\end{array}$ & 0.29 \\
\hline $\begin{array}{l}\text { Carbohydrate } \\
\text { (g) }\end{array}$ & $\begin{array}{l}340.65(332.99 ; \\
348.31)\end{array}$ & $\begin{array}{l}277.28(269.92 ; \\
284.64)\end{array}$ & $-66.018^{*}(-73.96 ;-58.08$ & $\begin{array}{l}345.21(336.15 \\
354.27)\end{array}$ & $\begin{array}{l}277.44(268.25 ; \\
286.62)\end{array}$ & $-68.08^{*}(-77.42 ;-58.73)$ & $+2.06(-10.10 ; 14.22)$ & 0.74 \\
\hline Protein (g) & $\begin{array}{l}103.60(100.84 \\
106.35)\end{array}$ & $97.08(93.57 ; 100.59)$ & $-4.94 *(-8.29 ;-1.59)$ & $102.05(98.20 ; 105.90)$ & $94.51(90.52 ; 98.49)$ & $-7.99^{*}(-13.00 ;-2.98)$ & $+3.05(-2.93 ; 9.03)$ & 0.32 \\
\hline Fat (g) & $81.04(77.99 ; 84.09)$ & $60.71(58.34 ; 63.09)$ & $-20.82^{*}(-24.15 ;-17.50)$ & 78.09 (74.54; 81.65) & $61.15(57.99 ; 64.32)$ & $-16.49^{*}(-20.42 ;-12.57)$ & $-4.33(-9.43 ; 0.78)$ & 0.13 \\
\hline Saturated fat (g) & $25.04(23.82 ; 26.26)$ & $17.51(16.71 ; 18.32)$ & $-7.37^{*}(-8.69 ;-6.05)$ & 23.67 (22.30; 25.05) & $18.24^{*}(17.04 ; 19.45)$ & $-5.06^{*}(-6.59 ;-3.53)$ & $-2.31(-4.31 ;-0.31)$ & 0.02 \\
\hline Fiber (g) & $28.31(26.90 ; 29.72)$ & $25.64(24.33 ; 26.95)$ & $-2.90 *(-4.56 ;-1.24)$ & $27.77(26.25 ; 29.30)$ & $22.54(21.16 ; 23.92)$ & $-5.60 *(-7.19 ;-4.02)$ & $+2.70(0.43 ; 4.98)$ & 0.03 \\
\hline Sodium (mg) & $\begin{array}{l}3267.45 \text { (3155.45; } \\
3379.44)\end{array}$ & $\begin{array}{l}2588.72(2478.87 ; \\
2698.56)\end{array}$ & $-647.68^{*}(-786.91 ;-508.45)$ & $\begin{array}{l}3120.46 \text { (2983.13; } \\
3257.79)\end{array}$ & $\begin{array}{l}2434.43 \text { (2307.64; } \\
2561.22)\end{array}$ & $-666.39 *(-840.62 ;-492.16)$ & $\begin{array}{l}+18.71 \text { (-202.50; } \\
\text { 239.92) }\end{array}$ & 0.87 \\
\hline Potassium (mg) & $\begin{array}{l}3536.57(3396.17 ; \\
3676.98)\end{array}$ & $\begin{array}{l}3337.41 \text { (3179.57; } \\
3495.24)\end{array}$ & $-212.49^{*}(-372.41 ;-52.57)$ & $\begin{array}{l}3533.50(3384.28 ; \\
3682.72)\end{array}$ & $\begin{array}{l}3055.77(2932.45 ; \\
3179.08)\end{array}$ & $-530.92^{*}(-681.85 ;-379.99)$ & $\begin{array}{l}+318.43(100.32 \\
536.54)\end{array}$ & 0.01 \\
\hline
\end{tabular}




\section{Conclusions}

Although differences in events between the two groups were not significant, data suggest that the lowest number of events observed in the intervention group is accentuated in the longer follow-up. Further studies with larger numbers of participants could clarify the role of nutrition education interventions in secondary prevention of coronary artery disease.

\section{Additional files}

Additional file 1: Raw database. All variables of baseline characteristics of participants and outcome measures. (XLSX $41 \mathrm{~kb}$ )

Additional file 2: Food intake dataset. Initial and final food intakes with the absolute and adjusted values of nutrients - carbohydrate (hc), protein (prot), fat, saturated fat (ags), fiber, sodium (na) and potassium (k). (XLSX 53 kb)

\section{Abbreviations}

AMl: Acute myocardial infarction; ARR: Absolute risk reduction; CABG: Coronary artery bypass graft; $\mathrm{Cl}$ : Confidence interval; HR: Hazard ratio; PCl: Percutaneous coronary intervention; RR: Risk ratio

\section{Funding}

Fundação de Amparo a Pesquisa do Estado de São Paulo (FAPESP) provided the financial support for this research, case number 2007/54652-8.

\section{Availability of data and materials}

The dataset supporting the conclusions of this article is included within the article and its additional file.

\section{Authors' contributions}

Designing the study: LPV, MRN. Collecting the data: LPV. Data analyses: LPV, JAS. Interpretation of data: all authors. Drafting the initial manuscript: LPV. Manuscript revision: all authors. All authors read and approved the final manuscript.

\section{Authors' information}

LPV: Postgraduate course in Preventive Medicine, Department of Faculdade de Medicina da Universidade de São Paulo.

\section{Competing interests}

The authors declare that they have no competing interests.

\section{Consent for publication}

Not applicable.

\section{Ethics approval and consent to participate}

All patients were instructed about the study and signed an informed consent form. The study was approved by local (Scientific Committee from Heart Institute) and by the Ethical Research Committee of the Hospital das Clínicas da Faculdade de Medicina de São Paulo, Brazil. The protocol number is $443 / 07$.

The name of the registered trial protocol is Feeding Education in Patients Submitted to Coronary Angioplasty (PTCA-Nutri), which can be accessed in: https://clinicaltrials.gov/ct2/show/NCT01028066?term=PTCA-Nutri\&rank=1

\footnotetext{
Author details

${ }^{1}$ Nutrition and Dietetic Service, Heart Institute (InCor) do Hospital das Clínicas da Faculdade de Medicina da Universidade de São Paulo, Av. Dr. Enéas de Carvalho Aguiar, 44. Cerqueira César, São Paulo, SP CEP: 05403-000, Brazil. ${ }^{2}$ Clinic Epidemiology Unit, Heart Institute (InCor) do Hospital das Clínicas da Faculdade de Medicina da Universidade de São Paulo, São Paulo, Brazil. ${ }^{3}$ Department of Public Health Nutrition, Faculty of Nutrition, Universidade Federal de Alagoas, Maceió, Brazil.
}

Received: 23 April 2016 Accepted: 18 November 2016 Published online: 29 November 2016

\section{References}

1. Rippe JM, Angelopoulos TJ. Lifestyle strategies for cardiovascular risk reduction. Curr Atheroscler Rep. 2014. doi:10.1007/s11883-014-0444-y.

2. Ornish D, Brown SE, Scherwitz LW, Billings JH, Armstrong WT, Ports TA, et al Can lifestyle changes reverse coronary heart disease?The Lifestyle Heart Trial. Lancet. 1990:336:129-33.

3. Maruthur NM, Wang NY, Appel LJ. Lifestyle interventions reduce coronary heart disease risk: results from the PREMIER Trial. Circulation. 2009;119:2026-31.

4. Estruch R, Ros E, Salas-Salvadó J, Covas Ml, Corella D, Arós F. Primary prevention of cardiovascular disease with a Mediterranean diet. N Engl J Med. 2013;368:1279-90.

5. Lisspers J, Sundin Ö, Öhman A, Hofman-Bang C, Rydén L, Nygren A. Long term effects of lifestyle behavior change in coronary artery disease: effects on recurrent coronary events after percutaneous coronary intervention. Health Psychol. 2005;24:41-8.

6. Bemelmans WJ, Broer J, Hulshof KF, Siero FW, May JF, Meyboom-de JB. Long-term effects of nutritional group education for persons at high cardiovascular risk. Eur J Public Health. 2004;14:240-5.

7. Aldana S, Greenlaw R, Diehl H, Salberg A, Merril R, Ohmine S, Thomas C. Effects of an intensive diet and physical activity modification program on the health risks of adults. J Am Diet Assoc. 2005;105:371-81.

8. Eshah NF, Bond AE, Froelicher ES. The effects of a cardiovascular disease prevention program on knowledge and adoption of a heart healthy lifestyle in Jordanian working adults. Eur J Cardiovasc Nurs. 2010;9:244-53.

9. Artinian NT, Fletcher GF, Mozaffarian D, Kris-Etherton P, Van Horn L, Lichtenstein $\mathrm{AH}$, et al. Interventions to promote physical activity and dietary lifestyle changes for cardiovascular risk factor reduction in adults: a scientific statement from the American Heart Association. Circulation. 2010;122:406-41.

10. Sposito AC, Caramelli B, Fonseca FA, Bertolami MC, Afiune Neto A, Souza $A D$, et al. IV Brazilian Guideline for Dyslipidemia and Atherosclerosis prevention: Department of Atherosclerosis of Brazilian Society of Cardiology. Arq Bras Cardiol. 2007;88(Supp I):2-19.

11. Dean AG, Sullivan KM, Soe MM. OpenEpi: Open Source Epidemiologic Statistics for Public Health, Version 2.2. http://www.openepi.com/, updated 2007/11/09. Accessed 17 Feb 2008.

12. Freire P. Pedagogia do oprimido [Pedagogy of the Oppressed]. 44th ed. São Paulo: Paz e Terra; 2006.

13. Brasil - Ministério da Saúde. Guia alimentar para a população brasileira: promovendo a alimentação saudável. Brasília: Secretaria de Atenção à Saúde/Coordenação-geral da Política de Alimentação e Nutrição; 2008. [Ministry of Health. Food Guide for the Brazilian population: promoting healthy eating. Brasilia: Department of Health Care/Coordination General for the Food and Nutrition Policy; 2008.

14. Philippi ST, Latterza AR, Cruz ATR, Ribeiro LC. Adapted food pyramid: a guide for a right food choice. Rev Nutr. 1999;12:65-80.

15. Brandão CR. O que é o método Paulo Freire [What is the Paulo Freire method?]. 14th ed. São Paulo: Brasiliense; 1988.

16. Feitosa SCF. Método Paulo Freire: princípios e práticas de uma concepção popular de educação. Tese de Mestrado, 1999, Paulo Freire method: principles and practices of a popular education concept. Master's thesis. 1999.

17. Sauvageot N, Leite S, Alkerwi A, Sisanni L, Zannad F, Saverio S, et al. Association of empirically derived dietary patterns with cardiovascular risk factors: a comparison of PCA and RRR methods. Plos One. 2016;11(8): e0161298. doi: 10.1371.

18. Viebig RF, Pastor-Valero M. Development of a food frequency questionnaire to study diet and non-communicable diseases in adult population. Rev Saude Publica. 2004;38:581-4.

19. Viebig RF, Pastor-Valero M, Scazufca M, Menezes PR. Fruit and vegetable intake among low income elderly in the city of São Paulo, Southeastern Brazil. Rev Saude Publica. 2009;43:806-3.

20. Vieira LP, Nobre MRC, Queiroz GG. Eating behavior and nutritional status in patients who underwent coronary angioplasty. Nutr Hosp. 2012;27:281-7.

21. Willet W, Stampfer M. Implications of total energy intake for epidemiologic analyses. In: Willett W, editor. Nutritional Epidemiology. 2nd ed. New York: Oxford University Press; 1998. p. 273-301.

22. de Graaf C, van der Gaag M, Kafatos A, Lennernas M, Kearney JM. Stages of dietary change among nationally-representative samples of adults in the European Union. Eur J Clin Nutr. 1997;51 Suppl 2:47-56. 
23. Prochaska JO, DiClemente CC, Norcross JC. In search of how people change. Applications to addictive behaviors. Am Psychol. 1992;47:1102-14.

24. lestra JA, Kromhout D, van der Schouw YT, Grobbee DE, Boshuizen HC, van Staveren WA. Effect size estimates of lifestyle and dietary changes on allcause mortality in coronary artery disease patients - A systematic review. Circulation. 2005;112:924-34.

25. Pi-Sunyer $X$. The Look AHEAD Trial: A review and discussion of its outcomes. Curr Nutr Rep. 2014;3:387-91.

26. Strid C, Lingfors $\mathrm{H}$, Fridlund B, Mårtensson J. Lifestyle changes in coronary heart disease - Effects of cardiac rehabilitation programs with focus on intensity, duration and content - systematic review. Open J Nurs. 2012;2: 420-30.

27. Pettman TL, Buckley JD, Misan GM, Coates AM, Howe PR. Health benefits of a 4-month group-based diet and lifestyle modification program for individuals with metabolic syndrome. Obes Res Clin Pract. 2009:3:221-35.

28. Liebman M. Promoting healthy weight: lessons learned from WIN the Rockies and other key studies. J Nutr Educ Behav. 2005;37 Suppl 2:S95-100.

Submit your next manuscript to BioMed Central and we will help you at every step:

- We accept pre-submission inquiries

- Our selector tool helps you to find the most relevant journal

- We provide round the clock customer support

- Convenient online submission

- Thorough peer review

- Inclusion in PubMed and all major indexing services

- Maximum visibility for your research

Submit your manuscript at www.biomedcentral.com/submit 